\title{
Determinants of depression among people with epilepsy in Central Ethiopia
}

\author{
Asrat Chaka' ${ }^{1}$,Tadesse Awoke ${ }^{2}$, Zegeye Yohannis ${ }^{1}$, Getinet Ayano ${ }^{1}$, Minale Tareke ${ }^{3 *}$, Andargie Abate ${ }^{3}$ \\ and Mulugeta Nega ${ }^{4}$
}

\begin{abstract}
Background: Depression is the most frequently and highly occurring mental disorders in epilepsy patients. When depression is comorbid with epilepsy, it leads to low employment and poor quality of life. Thus, the aim of this study was to assess the prevalence and associated factors of depression among people living with epilepsy in Central Ethiopia.

Methods: Institution-based cross-sectional study was conducted from April to May 2015 at Amanuel Mental Specialized and TikurAnbesa Hospitals, Addis Ababa, Ethiopia. Samples of 422 epilepsy patients were selected, and data on depression were collected using validated questionnaire using face-to-face interview technique. Logistic regression analysis was performed to assess predictors of depression.

Results: The study indicated that the prevalence of depression among people with epilepsy was $43.8 \%$. Factors associated with depression were being female (AOR 2.48; 95\% Cl, 1.61.3.81), being single (AOR 2.23; 95\% Cl 1.38-3.60), perceived stigma (AOR 2.47; 95\% Cl 1.59-3.83), medication adherence (AOR 2.85; 95\% Cl 1.64-4.96), and current substance use (AOR 2.10; 95\% Cl 1.34-3.30).

Conclusion: There is a high prevalence of depression among epilepsy patients. Early detection and prompt management of depressive symptoms are critically important in reducing depression burden among people living with epilepsy.
\end{abstract}

Keywords: Comorbidity, Depression, Epilepsy

\section{Introduction}

Epilepsy is a disease of the brain defined by at least two unprovoked (or reflex) Seizures occurring within $>24 \mathrm{~h}$ apart; one unprovoked (or reflex) seizure and a probability of further seizures similar to the general recurrence risk (at least 60\%) after two unprovoked seizures, occurring over the next 10 years [1]. It is a common neurological condition characterized by recurrent seizures and abnormal electrical activity in the brain that causes an involuntary change in body movement or function, sensation, awareness, or behavior [2]. More than $80 \%$ of people with epilepsy live in developing countries, and a

\footnotetext{
${ }^{*}$ Correspondence: minale23@gmail.com

${ }^{3}$ College of Medicine and Health Science, Bahir Dar University, Bahir Dar, Ethiopia

Full list of author information is available at the end of the article
}

majority of them do not have recourse to any effective treatment [3].

Depression is highly prevalent in the patient with epilepsy and is the most frequent comorbid psychiatric problem [4]. According to Diagnostic and Statistical Manual of Mental Disorders, Fifth Edition (DSM-5), depressive disorder is defined as at least one of the symptoms, either depressed mood or loss of interest or pleasure for at least 2 weeks, and includes at least other four symptoms from a list of criteria items, which are severe enough to cause severe distress or impairment in executing important functional roles [5].

Data from population-based studies have revealed a more complex, bidirectional relation between the two disorders, whereby not only are people with epilepsy at greater risk of developing depression but also people with depression are at greater risk of developing epilepsy. The

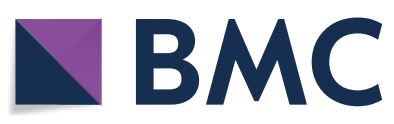

(c) The Author(s) 2018. This article is distributed under the terms of the Creative Commons Attribution 4.0 International License (http://creativecommons.org/licenses/by/4.0/), which permits unrestricted use, distribution, and reproduction in any medium, provided you give appropriate credit to the original author(s) and the source, provide a link to the Creative Commons license, and indicate if changes were made. The Creative Commons Public Domain Dedication waiver (http://creativecommons.org/ publicdomain/zero/1.0/) applies to the data made available in this article, unless otherwise stated. 
existing common neurobiological pathogenic mechanisms shared by depressive disorders and epilepsy include neurotransmitter disturbances in the central nervous system such as serotonin, norepinephrine, dopamine, glutamate, and gamma-aminobutyric acid (GABA); endocrine disturbances such as hyperactive hypothalamic pituitary-adrenal axis, resulting in high serum concentrations of cortisol; and inflammatory mechanisms (in particular, interleukin- $1 \beta$ has been found to play a pathogenic role in patients with mood disorders) [6].

Depression is the most frequent psychiatric comorbidity in people with epilepsy with a prevalence rate ranging from 9.5 to $63 \%$ [7-12]. It leads to underemployment, lower rates of marriage, and a greater chance of social isolation when compared to counterparts $[13,14]$. The high magnitude of depression among people living with epilepsy negatively influences their quality of life and increases suicidal tendency $[15,16]$. Factors such as side effects of antiepileptic drugs, perceived stigma, fear of seizures, discrimination, joblessness, lack of social support, increased seizure frequency, and nonadherence to their medication have contributed to inducing depression among epilepsy patients $[17,18]$.

Despite this burden and consequences, there is a limited literature on the magnitude of depression and associated factors in people with epilepsy in the study area. Therefore, this study was intended to fill the gaps by assessing the prevalence and associated factors of depression among people living with epilepsy. It also helps to integrate mental health service in primary healthcare unit by early diagnosis and timely treatment of comorbid cases.

\section{Methods}

\section{Study settings and population}

Institution-based cross-sectional study was conducted from April to May 2015 at Amanuel Mental Specialized and TikurAnbesa Hospitals neurology clinics, located in Addis Ababa (capital city of Ethiopia). Amanuel Mental Specialized Hospital (AMSH) and TkurAnbesa Hospital $(\mathrm{TAH})$ are the largest referral centers for people in Ethiopia as well as served as being medical teaching institutions. The AMSH and TAH have three and two neurologic outpatient clinics, respectively. Both hospitals provide medical and neurologic care.

The study populations comprised all epilepsy patients who were receiving treatments in their respective hospitals. All patients aged 18 years and above who have been diagnosed with epilepsy and provided with treatment in the outpatient epilepsy clinics in both hospitals were included in the study. Patients unable to communicate and seriously ill were excluded from the study.

\section{Sample size and Sampling procedures}

The sample size was calculated using a single population proportion formula $\left[n_{\mathrm{o}}=\left(Z \alpha_{/ 2}\right)^{2} \times(P-q)\right) / d^{2}$, where $n_{\mathrm{o}}$ is the minimum sample size, $Z$ the standardized normal distribution value at $\alpha / 2, P$ the proportion of depression, and $d$ is the margin of error]. By taking the proportion of depression at $49.3 \%$ [19], $Z \alpha_{/ 2}$ at $95 \%$ CI (1.96), and tolerable margin of error at (0.05), the minimum sample size was 384 . By adding $10 \%$ for nonresponse rate, 423 participants were involved in the study.

Sampling interval was determined by dividing the total study population who had followed up during one month before data collection period (1600) by total sample size (422). Sampling fraction is $1600 / 422 \approx 4$. Hence, the sample interval is 4 . The first study population was selected by lottery method, and the next study participants were chosen at regular intervals (every 4th), and the selected respondents were interviewed by data collectors.

\section{Data collection and quality assurance}

Data were collected using instruments that measure depression, perceived stigma, Medication Adherence Scale, and social support-related questionnaires. The Patient Health Questionnaire (PHQ)-9 is the nine-item depression scale which is a powerful tool for clinicians to screen depression and monitor treatment response. The tool is based directly on the nine diagnostic criteria for major depressive disorder among epilepsy patients [20]. PHQ-9 is validated and extensively used in Ethiopia [21, 22 ]. The score of greater than or equal to 5 was considered to indicate probable depression in patients in this study. Patient medication adherence was measured using self-reported questions.

Perceived stigma was assessed via a three-item stigma scale with an overall possible score ranging from 0 (no felt stigma) to 3 (maximally felt stigma) [23]. Social support was measured by the three Oslo scale of social support measurement [24].

The questionnaire was designed and modified appropriately and translated into local language (Amharic) to be understood by all participants and translated back to English again to ensure its consistency. Training was given for four data collectors (psychiatry nurses) and one supervisor (BSc Nursing) for 2 days. The pretest was done at TikurAnbesa hospital 2 weeks before the day of actual data collection. The data collectors were supervised daily, and the filled questionnaires were checked properly by the supervisor and the principal investigator. 


\section{Data management and processing}

The coded data were checked, cleaned, and entered into epi.info version 3.5 and then exported into Statistical Package for the Social Sciences (SPSS) window version 20 for analysis. Descriptive statistic was used to explain the study participants in relation to study variable. Bivariate and multivariate logistic regression analyses were conducted to identify associated factors of depression among people with epilepsy. The strength of the association was interpreted by odds ratio with 95\% CI, and the $p$-value less than 0.05 was considered as statistically significant.

\section{Ethical consideration}

Ethical clearance was obtained after approval from the Institutional Review Board (IRB) of the College of Medicine and Health Sciences, the University of Gondar and from Amanuel Mental Specialized Hospital. The data collectors have clearly explained the aims of the study to the study participants. Information was collected after obtaining written consent from each participant. The right to exercise refusal was given to the study participants as well as their discontinuation from participation at any point in time. Confidentiality was maintained throughout the study. Those study participants suffering from recurrent severe suicidal thought was treated by communicating with psychiatry case team.

\section{Result}

\section{Sociodemographic characteristics}

The mean age of respondents was 31.57 ( \pm SD 9.91). Nearly one-third (33.9\%) of the respondents were between 25- and 34-aged groups and almost half of them were single (50.2\%) by marital status. A majority of them were living in the urban area (88.2\%) (Table 1).

\section{Clinical- and medication-related characteristics}

The majority (86\%) of them had no family history of mental illness. Among the study respondents, nearly one-third (36\%) had more than 10 years of duration of illness. Most (66.4\%) of the study respondents were taking more than one antiepileptic drugs, had social support $(85.3 \%)$, and had felt no stigma (62.3\%) (Table 2).

\section{Substance related factors of the respondents}

Most (67.8\%) of the study participants had no history of substance use; however, the remaining (32.2\%) used the substance. Among the total study participants who had used the substance, 79 (18.7\%) were reported drinking alcohol (Fig. 1).
Table 1 Sociodemographic distribution of epilepsy patients on follow up at AMSH and TAH, 2015

\begin{tabular}{|c|c|c|}
\hline Variables & Numbers & Percent (\%) \\
\hline \multicolumn{3}{|l|}{ Sex } \\
\hline Male & 249 & 59.0 \\
\hline Female & 173 & 41 \\
\hline \multicolumn{3}{|l|}{ Age } \\
\hline $18-24$ & 105 & 24.9 \\
\hline $25-34$ & 143 & 33.9 \\
\hline $35-44$ & 113 & 26.8 \\
\hline $45-54$ & 48 & 11.4 \\
\hline$\geq 55$ & 13 & 3.1 \\
\hline \multicolumn{3}{|l|}{ Ethnicity } \\
\hline Amhara & 138 & 32.7 \\
\hline Oromo & 126 & 29.9 \\
\hline Tigre & 24 & 5.7 \\
\hline Gurage & 119 & 28.2 \\
\hline Others & 15 & 3.6 \\
\hline \multicolumn{3}{|l|}{ Marital status } \\
\hline Single & 212 & 50.2 \\
\hline Divorce & 58 & 13.7 \\
\hline Widowed & 9 & 2.1 \\
\hline Married & 143 & 33.9 \\
\hline \multicolumn{3}{|l|}{ Religion } \\
\hline Orthodox & 270 & 64.0 \\
\hline Muslim & 98 & 23.0 \\
\hline Protestant & 54 & 12.6 \\
\hline \multicolumn{3}{|l|}{ Residence } \\
\hline Urban & 372 & 88.2 \\
\hline Rural & 50 & 11.8 \\
\hline \multicolumn{3}{|l|}{ Education } \\
\hline Unable to read and write & 24 & 5.7 \\
\hline Primary (1-8) & 145 & 34.4 \\
\hline Secondary (9-12) & 172 & 40.8 \\
\hline Diploma and degree & 81 & 19.2 \\
\hline \multicolumn{3}{|l|}{ Occupation } \\
\hline Not employed & 41 & 9.7 \\
\hline Employed & 381 & 90.3 \\
\hline \multicolumn{3}{|l|}{ With whom living now } \\
\hline Family & 396 & 93.8 \\
\hline Alone & 14 & 3.3 \\
\hline Relative/friend & 12 & 2.8 \\
\hline
\end{tabular}

\section{Prevalence of depression among epilepsy patients}

The distribution of PHQ-9 among respondents showed a mean score and standard deviation of $4.83 \pm 4.68$. Using cutoff point of five and above, $43.8 \%$ of the respondents had depression with $95 \%$ confidence interval $(38.9 \%, 48.8 \%)$. More females $(52.4 \%)$ were affected by depression than males (47.6\%) (Table 3). 
Table 2 Description of clinical and psychosocial factors of patients with epilepsy at AMSH and TAH, 2015

\begin{tabular}{llcl}
\hline Variables & Frequency & Numbers & Percent (\%) \\
\hline Family history of mental & Yes & 59 & 14 \\
illness & No & 363 & 86 \\
Seizure frequency per & No seizure & 243 & 57.6 \\
month & $1-3$ & 173 & 41.0 \\
& 4 and above & 6 & 1.4 \\
Duration of epilepsy illness & $<1$ year & 19 & 4.5 \\
& $1-5$ years & 115 & 27.3 \\
& 6-10 years & 136 & 32.2 \\
Types of epilepsy diagnosed & Grandmal & 251 & 59.5 \\
& Petimal & 108 & 25.6 \\
Type of antiepileptic drug & Other & 63 & 14.9 \\
& Mono therapy & 142 & 33.6 \\
Medication adherence & Polytherapy & 280 & 66.4 \\
& Adherence & 330 & 78.2 \\
Social support & Poor adherence & 92 & 21.8 \\
Perceived stigma & Yes & 360 & 85.3 \\
& No & 62 & 14.7 \\
& No felt stigma & 263 & 62.3 \\
& Felt stigma & 159 & 37.7 \\
\hline
\end{tabular}

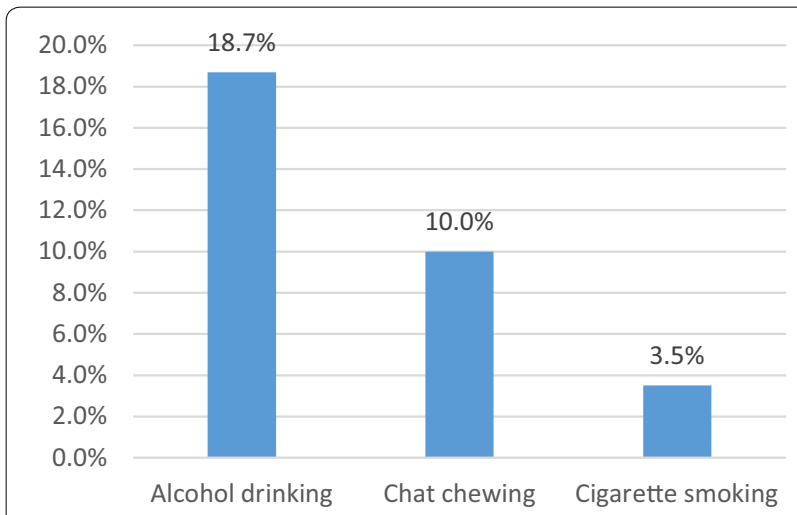

Fig. 1 Bar graph showing the distribution of current substance use among epilepsy patients at AMSH and TAH, 2015

\section{Factors associated with depression among epilepsy patients}

The associations of all potential explanatory variables and depression were checked using logistic regression model. However, only being female, single, perceived stigma, poor medication adherence, and current use of substance were significantly associated with depression in bivariate and multivariate logistic regression $(p<0.05)$.

Being female was 2.6 times more likely to have depression when compared to males (AOR 2.62, 95\% CI
Table 3 Factors associated with depression among epilepsy patients at under follow up at AMSH and TASH, 2015

\begin{tabular}{|c|c|c|c|c|}
\hline \multirow[t]{2}{*}{ Variables } & \multicolumn{2}{|c|}{ Depression } & \multirow[t]{2}{*}{ COR $(95 \% \mathrm{Cl})$} & \multirow[t]{2}{*}{ AOR $(95 \% \mathrm{Cl})$} \\
\hline & Yes & No & & \\
\hline \multicolumn{5}{|l|}{ Sex } \\
\hline Female & 97 & 76 & $2.36(1.56-3.47)$ & $2.62(1.68-4.09)^{*}$ \\
\hline Male & 88 & 161 & 1.00 & 1.00 \\
\hline \multicolumn{5}{|l|}{ Marital status } \\
\hline Single & 110 & 102 & $2.35(1.51-3.66)$ & $2.04(1.25-3.34)^{*}$ \\
\hline $\begin{array}{l}\text { Divorced/sepa- } \\
\text { rated }\end{array}$ & 27 & 31 & $1.89(1.01-3.54)$ & \\
\hline Widowed & 3 & 6 & $1.089(0.26-4.55)$ & \\
\hline Married & 45 & 98 & 1.00 & 1.00 \\
\hline \multicolumn{5}{|c|}{ Medication adherence } \\
\hline Yes & 162 & 168 & 1.00 & 1.00 \\
\hline No & 23 & 69 & $2.89(1.72-4.86)$ & $2.65(1.52-4.65)^{*}$ \\
\hline \multicolumn{5}{|l|}{ Perceived stigma } \\
\hline No & 94 & 169 & 1.00 & 1.00 \\
\hline Yes & 91 & 68 & $2.40(1.60-3.60)$ & $2.65(1.65-4.07)^{*}$ \\
\hline \multicolumn{5}{|c|}{ Current substance use (alcohol, chat, cigarette) } \\
\hline Yes & 77 & 59 & $2.15(1.42-3.26)$ & $2.14(1.34-3.39)^{*}$ \\
\hline No & 108 & 178 & 1.00 & 1.00 \\
\hline
\end{tabular}

* $p<0.05 ; 1.00=$ Reference; $C O R$ crude odds ratio, $A O R$ adjusted odds ratio

1.68-4.09). Similarly, being single was around twice more likely to have depression compared to married participants (AOR 2.04, 95\% CI 1.25-3.34).

Moreover, those who have poor medication adherence and having perceived stigma had close to three odds of having depression compared to their counterparts (AOR 2.65, 95\% CI 1.52-4.65; AOR 2.65, 95\% CI 1.65-4.07, respectively). In addition, current substance use (alcohol drinking, Khat chewing, and cigarette smoking) were significantly associated with depression. Depression was two times more likely among current substance users (AOR 2.14, 95\% CI 1.34-3.39) (Table 3).

\section{Discussion}

In this study, the prevalence rate of depression among epilepsy patients was $43.8 \%$ (38.9, $48.8 \%)$. It is consistent with the study done at the University of Gondar Hospital (45.2\%) [25] and Sudan (45.5\%) [26].

This finding was lower than the result from the study conducted at the Jimma University Specialized Hospital (49.3\%) [19]. Other studies conducted in Nigeria and Gaza stated that depression had been prevalent among 85.5 and $63 \%$ of participants, respectively $[9,27]$ which are very high compared with the current study, and they were almost three times higher in magnitude than that reported in a study done in Canada [11]. This difference 
might be due to the sociocultural variation and instrument, since those authors used BDI which has items similar to somatic complaints, and this might have led to overestimating the prevalence.

However, the current study's finding regarding prevalence rate is higher than the report described in Amanuel Mental Specialized Hospital (33.3\%) [28], Kenya (16.5\%) [29], Iran (9.5\%) [8], Thailand (20\%) [30], and Greek (22.5\%) [31]. These discrepancies might be due to the difference in study participants, method, culture, time, and settings.

In this study, the researchers found a high prevalence of depression among female compared to male respondents which are consistent with the study done in Gaza [9]. However, the study in Nigeria and Ethiopia [19, 27] revealed that no significant relationship between gender and depression in people with epilepsy. The difference is most likely due to diverse methodological approaches, cultural variation, and different instruments they used to measure depression. In general, females faced difficulty in performing normal activities of daily living, and they might face several risks or hardships with regard to reproductive activity and pregnancy. Furthermore, women with epilepsy face difficulty in decision-making with regard to important major life events such as marriage or bearing children. Thus, these consequences might increase depression among females.

With regard to marital status in this study, those who were married were less likely to be depressed compared to those with single status, and having another marital status. This finding was consistent with the previous study in Jimma Ethiopia [19] but inconsistent with other studies in which the authors found no significant difference among different marital statuses [27,28]. This might be due to marriage-related change of lifestyles because of some kind of guardian-like protective effect of the marital status where adherence to healthy activities is greatly increased-and behaviors leading to health risks are reduced. Moreover, married people also have higher levels of emotional support.

The study has also shown that patients who were not adherent to their medication had depression compared to those who were adherent. This hypothesis is supported by previous studies $[19,25]$. The high rates of poor adherence demonstrated in this study are causing concerns, given the consequences of antiepileptic discontinuation. It might be assumed that patients who discontinue medication will be more likely to relapse and have very poor and less control over the disease than those who continue medications.

Moreover, in this study, stigma was associated with depression which is supported by different studies [19, 28]. The previous study conducted in Ethiopia among epilepsy among patients found perceived stigma to be a common problem among people living with epilepsy [32]. This is because people with epilepsy might be overprotected and restricted from doing many activities by their family members, friends, or teachers. Overprotection arising from stigmatization can have severe consequences. Eventually, this stigma shatters a person's hope and self-esteem leading to negative outcomes related to recovery including depressive symptoms, social avoidance, and a preference for adopting avoidance of coping strategies.

In this particular study, current substance use has a significant association with depression. This result is supported by Epilepsy Action Australia report [33]. Substance use among people taking antiepileptic medications is likely to be more sensitive to the effects of substances. The substance can interfere with the metabolism of these medications and therefore increase the chance of seizures. Some medications can enhance the toxic effects of alcohol, and people can feel severely intoxicated after drinking only a small amount. Skipping a dose, taking extra medication, or altering the time of taking regular antiepileptic medications before drinking will not alter this reaction but may cause additional adverse effects or seizures [33].

In general, the implication of this finding indicates that people living with epilepsy need strong counseling in terms of adherence, by way of creating awareness in the community and addressing misperception issues attached to epilepsy. Collaborative efforts among different stakeholders and clinicians are recommended to bring effective management strategies to neurologic clinics. In addition, generating additional evidence through further research is required.

A limitation of this study was that it was not possible to clarify the cause-effect relationship between depression and epilepsy due to the cross-sectional nature of the study. A prospective study could help to establish clearly whether epilepsy predisposes to depression or a consequence of depression predispose to epilepsy. Another limitation includes recall bias-regarding the duration of illness and substance-use-related factor-which was not assessed by a standard tool.

\section{Conclusion}

The finding showed that there is a high prevalence of comorbid depression (43.8\%) among epilepsy patients at the AMSH and TAH. The epilepsy-related sociodemographic variables like being female, single, and clinicalrelated factors including poor medication adherence, current substance use, and perceived stigma were significantly associated with depression. Early recognition of depression symptoms in people with epilepsy should 
be of great concern for healthcare providers to help them provide appropriate counseling regarding adherence and substance use.

\begin{abstract}
Author details
${ }^{1}$ Department of Psychiatry, Amanuel Mental Specialized Hospital, Addis Ababa, Ethiopia. ${ }^{2}$ Department of Epidemiology and Biostatistics, University of Gondar, Gondar, Ethiopia. ${ }^{3}$ College of Medicine and Health Science, Bahir Dar University, Bahir Dar, Ethiopia. ${ }^{4}$ College of Medicine and Health Science, Haramaya University, Harer, Ethiopia.
\end{abstract}

\section{Acknowledgements}

The authors would like to thank the University of Gondar and AMSH. The authors are also grateful to data collectors, supervisors, and study participants, and their important contribution for this study is duly acknowledged.

\section{Authors' contributions}

All authors contributed toward data analysis, drafting, and critically revising the paper, and agree to be accountable for all aspects of the work. All authors read and approved the final manuscript.

\section{Competing interests}

The authors have declared that there are no conflicts of interest in this work.

\section{Consent for publication}

Not applicable.

\section{Ethics approval and consent to participate}

Ethical clearance was obtained from the Institutional Review Board (IRB) of the College of Medicine and Health Sciences, University of Gondar and from the Amanuel Mental Specialized Hospital (AMSH). The data collectors have clearly explained the aims of the study to the study participants. Information was collected after obtaining written consent from each participant. The right was given to the study participants to refuse or discontinue participation at any time. Confidentiality was maintained throughout the study. Those study participants suffering from recurrent severe suicidal thought were treated by communicating with psychiatry case team.

\section{Funding}

This research work is funded by the University of Gondar and Amanuel Mental Specialized Hospital.

\section{Publisher's Note}

Springer Nature remains neutral with regard to jurisdictional claims in published maps and institutional affiliations.

Received: 13 February 2018 Accepted: 5 June 2018

Published online: 13 June 2018

\section{References}

1. Mathern G, Nehlig A. ILAE Adopts an operational definition of epilepsy intended to be used clinically. Flower Mound: International League Against Epilepsy; 2014.

2. Fisher RS, Acevedo C, Arzimanoglou A, Bogacz A, Cross JH, Elger CE, Engel J Jr, Forsgren L, French JA, Glynn M, et al. ILAE Official Report: a practical clinical definition of epilepsy. Epilepsia. 2014;55(4):475-82.

3. De Boer HM, Mula M, Sander JW. The global burden and stigma of epilepsy. Epilepsy Behav. 2008;12(4):540-6.

4. Gilliam FG, Barry JJ, Hermann BP, Meador KJ, Vahle V, Kanner AM. Rapid detection of major depression in epilepsy: a multicentre study. Lancet Neurol. 2006:5(5):399-405.

5. American Psychiatric Association, Mula M. Diagnostic and statistical manual of mental disorders. 5th ed. Washington, DC: American Psychiatric Association; 2013.

6. Mula M. Neuropsychiatric symptoms of epilepsy. Cham: Springer; 2016.

7. Kanner AM, Schachter SC, Barry JJ, Hersdorffer DC, Mula M, Trimble M, Hermann B, Ettinger AE, Dunn D, Caplan R. Depression and epilepsy: epidemiologic and neurobiologic perspectives that may explain their high comorbid occurrence. Epilepsy Behav. 2012;24(2):156-68.

8. Asadi-Pooya A, Sperling M. Depression and anxiety in patients with epilepsy, with or without other chronic disorders. Iran Red Crescent Med J. 2011;13(2):112-6

9. Sheer AA: Depression among epileptic patients in Governmental Community Mental Health Centers in Gaza Strip. Gaza: The Islamic University - Gaza; 2012.

10. Todorova K, Arnaoudova M. Depressive disorders in epilepsy. J IMAB Annu Proc (Sci Pap.). 2010;16:3.

11. Wong ST, Manca D, Barber D, Morkem R, Khan S, Kotecha J, Williamson T, Birtwhistle R, Patten $\mathrm{S}$. The diagnosis of depression and its treatment in Canadian primary care practices: an epidemiological study. CMAJ Open. 2014;2(4):E337.

12. Nidhinandana $S$, Chinvarun $Y$, Sithinamsuwan $P$, Udommongkol $C$, Suwantamee J, Wongmek W, Suphakasem S. Prevalence of depression among epileptic patients at Phramongkutklao Hospital. J Med Assoc Thai. 2007;90(1):32.

13. Baker GA. The psychosocial burden of epilepsy. Epilepsia. 2002:43(s6):26-30.

14. Nabukenya AM, Matovu JK, Wabwire-Mangen F, Wanyenze RK, Makumbi F. Health-related quality of life in epilepsy patients receiving anti-epileptic drugs at National Referral Hospitals in Uganda: a cross-sectional study. Health Qual Life Outcomes. 2014;12(1):1.

15. Gabb MG, Barry JJ. The link between mood disorders and epilepsy. J Adv Med. 2005;5(6):S572-8.

16. Kralj-Hans I, Goldstein LH, Noble AJ, Landau S, Magill N, McCrone P, Baker G, Morgan M, Richardson A, Taylor S. Self-management education for adults with poorly controlled epILEpsy [SMILE (UK)]: a randomised controlled trial protocol. BMC Neurol. 2014;14:69.

17. Grabowska-Grzyb A, Jędrzejczak J, Nagańska E, Fiszer U. Risk factors for depression in patients with epilepsy. Epilepsy Behav. 2006;8(2):411-7.

18. Jones R, Butler J, Thomas V, Peveler R, Prevett M. Adherence to treatment in patients with epilepsy: associations with seizure control and illness beliefs. Seizure. 2006;15(7):504-8.

19. Tsegabrhan H, Negash A, Tesfay K, Abera M. Co-morbidity of depression and epilepsy in Jimma University specialized hospital, Southwest Ethiopia. Neurol India. 2014;62(6):649.

20. Kroenke K, Spitzer R, Williams J. The PHQ-9: validity of a brief depression severity measure. J Gen Intern Med. 2001;16(9):606-13.

21. Gelaye B, Williams MA, Lemma S, Deyessa N, Bahretibeb Y, Shibre T, Wondimagegn D, Lemenhe A, Fann JR, Vander Stoep A. Validity of the patient health questionnaire-9 for depression screening and diagnosis in East Africa. Psychiatry Res. 2013;210(2):653-61.

22. W/giorgis T, Wordofa B. Prevalence of depression and associated factors among adult diabetic patients attending outpatient department, at Felege Hiwot Referral Hospital, Bahir Dar, Northwest Ethiopia. Int J Health Sci Res (IJHSR). 2016;6(9): 264-276.

23. Pungrassami P, Kipp AM, Stewart PW, Chongsuvivatwong V, Strauss R, Van Rie A. Tuberculosis and AIDS stigma among patients who delay seeking care for tuberculosis symptoms. Int J Tuberc Lung Dis. 2010;14(2):181-7.

24. Bøen $\mathrm{H}$. Characteristics of senior centre users-and the impact of a group programme on social support and late-life depression. Norsk Epidemiol. 2012;22(2):261-9

25. Bifftu BB, Dachew BA, Tiruneh BT, Birhan Tebeje N. Depression among people with epilepsy in Northwest Ethiopia: a cross-sectional institution based study. BMC Res Notes. 2015;8:585.

26. Saadalla A, Elbadwi A. Depression among Sudanese epileptic patients. Indian J Basic Appl Med Res. 2016;5(4):808-11.

27. Onwuekwe IO, Ekenze OS, Bzeala-Adikaibe, Ejekwu J. Depression in patients with epilepsy: a study from Enugu, South East Nigeria. Ann Med Health Sci Res. 2012;2(1):10-3.

28. Tegegne MT, Mossie TB, Awoke AA, Assaye AM, Gebrie BT, Eshetu DA. Depression and anxiety disorder among epileptic people at Amanue Specialized Mental Hospital, Addis Ababa, Ethiopia. BMC Psychiatry. 2015;15:210.

29. Kiko N. Prevalence and factors associated with depression among patients with epilepsy in a Kenyan tertiary care hospital. Nairobi: Aga Khan University; 2013. 
30. Phabphal K, Sattawatcharawanich S, Sathirapunya P, Limapichart K. Anxiety and depression in Thai epileptic patients. Med J Med Assoc Thai. 2007;90(10):2010.

31. Zis P, Yfanti P, Siatouni A, Tavernarakis A, Gatzonis S. Determinants of depression among patients with epilepsy in Athens, Greece. Epilepsy Behavior. 2014;33:106-9.
32. Tegegne MT, Awoke AA. Perception of stigma and associated factors in people with epilepsy at Amanuel Specialized Mental Hospital, Addis Ababa, Ethiopia. Int J Psychiatry Clin Pract. 2016;21(1):58-63.

33. Epilepsy Action Australia. Seizure smart: Alcohol and Epilepsy. 2011. Accessed 17 Jan 2017.
Ready to submit your research? Choose BMC and benefit from:

- fast, convenient online submission

- thorough peer review by experienced researchers in your field

- rapid publication on acceptance

- support for research data, including large and complex data types

- gold Open Access which fosters wider collaboration and increased citations

- maximum visibility for your research: over $100 \mathrm{M}$ website views per year

At BMC, research is always in progress.

Learn more biomedcentral.com/submissions 